6. Giesbrecht GG, Bristow GK. A second postcooling afterdrop: more evidence for a convective mechanism. J Appl Physiol (1985). 1992;73:1253-1258.

7. Brown DJ, Brugger H, Boyd J, Paal P. Accidental hypothermia. N Engl J Med. 2012;367:1930-1938.

8. Van der Ploeg G, Goslings JC, Walpoth BH, Bierens JJLM. Accidental hypothermia: rewarming treatments, complications and outcomes from one university medical centre. Resuscitation. 2010;81:1550-1555.

9. Kornberger E, Schwarz B, Lindner KH, Mair P. Forced air surface rewarming in patients with severe accidental hypothermia. Resuscitation. 1999;41:105-111.

10. Roggla M, Frossard M, Wagner A, Holzer M, Bur A, Roggla G. Severe accidental hypothermia with or without hemodynamic instability: rewarming without the use of extracorporeal circulation. Wien Klin Wochenschr. 2002;114:315-320.

\section{Hypothermia Evidence, Afterdrop, and Guidelines}

\section{To the Editor:}

We thank Brown et al for their response ${ }^{1}$ to our article "Wilderness Medical Society practice guidelines for the out-of-hospital evaluation and treatment of accidental hypothermia." 2 We did our best to use the available evidence to provide useful guidelines. Although we agree that some aspects regarding management of accidental hypothermia are controversial, the basics of hypothermia pathophysiology are well established. We disagree with the assessment of Brown et al that the evidence is not sufficiently robust to guide treatment.

The basis of our recommendation to delay standing or walking a mildly hypothermic patient for 30 minutes is related to the potential for afterdrop as well as hypotension with clinical deterioration. ${ }^{3,4}$ We should have been more explicit that this recommendation does not apply to a mildly hypothermic patient who is already walking, and may not be advisable when rescuers have limited resources to provide shelter and rewarming. We advise practical and sensible application of the guidelines rather than strict adherence. Rescue personnel should do the best they can under the circumstances.

Brown et al counted the types of studies in our list of references. We reviewed all the relevant studies we could identify. In the supplemental materials, ${ }^{2}$ we mentioned that the experimental physiology randomized clinical trials we cited were limited to studying nonhypothermic or mildly hypothermic subjects. The subjects were generally young and healthy. It is probable that afterdrop would be greater and adverse effects more likely in older, less healthy, and more severely hypothermic patients, especially when hypothermia is combined with volume depletion and exhaustion under field conditions.
Brown et al suggest that it would be better to wait for stronger evidence to make Grade 1 recommendations. We used the classification system of the American College of Chest Physicians in which recommendations are Grade 1 (strong) or Grade 2 (weak). ${ }^{5}$ The strength of evidence is rated separately by a letter. For example, Grade $1 \mathrm{~A}$ is a strong recommendation based on strong evidence. Providers of medical care often must act with incomplete information, especially in the prehospital setting. We attempted to be conservative in our recommendations to avoid harm to patients. It is appropriate to make strong recommendations based on low-quality evidence when potential benefits clearly seem to outweigh risks. Guidelines that make mainly Grade 2 (weak) recommendations do not provide much guidance to those who use them.

We agree with Brown et al that organ failure, particularly ventricular fibrillation causing circulatory arrest, is important. It is the main cause of death due to hypothermia. We also remind our readers that "there is great variation among individuals in response to core temperature, as with any other physiologic parameter."

There is good evidence to suggest that afterdrop and peripheral vasodilation are clinically important and should be minimized in moderate and severe hypothermia to decrease morbidity and mortality. ${ }^{3,6-8}$ Experimental evidence in humans demonstrates that circulation contributes more to afterdrop than conduction. ${ }^{9}$ It is not possible to decrease the conductive component of afterdrop, but it is possible to limit the contribution of circulation.

We do not state or imply that rewarming causes afterdrop. Any intervention that increases blood flow to cold extremities, including some rewarming methods, increases afterdrop. The studies that Brown et al cite in which hypothermic patients were rewarmed without afterdrop were in-hospital studies. The patients likely had already experienced afterdrop in the prehospital phase. Our recommendations are to avoid movement or warming of extremities initially to limit afterdrop caused by return of cold peripheral blood to the core.

Brown et al are correct that rescue collapse occurs in terrestrial rescue. It is usually impractical to measure core temperature before rescue collapse. A patient who has had rescue collapse is assumed to have been moderately or severely hypothermic. For this reason, there is unlikely to be a report of rescue collapse of a mildly hypothermic patient without comorbidities. Like Brown et al, we recommend giving a mildly hypothermic patient additional insulation and calories. For the source of calories, we recommend high carbohydrate liquids and food. ${ }^{2}$ If adequate resources are not available, the patient might need to walk to safety, with an 
observation period that is limited to the time it takes to insulate and provide calories, with an increased risk of rescue collapse.

We would agree with Brown et al not to limit standing or walking of mildly hypothermic patients if we could determine reliably which patients are only very mildly hypothermic. Owing to extreme variability in responses to hypothermia, this determination cannot be based reliably on clinical evaluation. Field measurement of core temperature is also not sufficiently accurate. If we erred in our recommendations, it was an attempt to err on the side of caution.

Ken Zafren, MD

International Commission for Mountain Emergency Medicine (ICAR MEDCOM) Division of Emergency Medicine Department of Surgery Stanford University School of Medicine Stanford, CA, USA

Gordon G. Giesbrecht, PhD Faculty of Kinesiology and Recreation Management Departments of Anesthesia and Emergency Medicine University of Manitoba Winnipeg, Manitoba, Canada

Daniel F. Danzl, MD Department of Emergency Medicine University of Louisville School of Medicine Louisville, KY, USA

Hermann Brugger, MD International Commission for Mountain Emergency Medicine (ICAR MEDCOM) European Academy Institute of Mountain Emergency Medicine Bolzano, Italy

Emily B. Sagalyn, MD, MPH University of Nevada School of Medicine Reno, NV, USA

Beat Walpoth, MD Service of Cardiovascular Surgery University Hospital of Geneva Geneva, Switzerland

Eric A. Weiss, MD Paul S. Auerbach, MD Division of Emergency Medicine Department of Surgery
Stanford University School of Medicine Stanford, CA, USA

Scott E. McIntosh, MD, MPH Mária Némethy, MD

Marion McDevitt, DO, MPH Division of Emergency Medicine University of Utah Salt Lake City, UT, USA

Jennifer Dow, MD Alaska Regional Hospital, Anchorage, AK, USA; Denali National Park and Preserve, AK, USA

Robert B. Schoene, MD University of Washington Seattle, WA, USA

George W. Rodway, PhD, APRN Division of Health Sciences University of Nevada, Reno, NV, USA

Peter H. Hackett, MD Division of Emergency Medicine Altitude Research Center

University of Colorado School of Medicine Denver, CO, USA; Institute for Altitude Medicine, Telluride, CO, USA

Brad L. Bennett, PhD Military \& Emergency Medicine Department F. Edward Hébert School of Medicine Uniformed Services University of the Health Sciences Bethesda, MD, USA

Colin K. Grissom, MD Division of Pulmonary and Critical Care Medicine Intermountain Medical Center University of Utah Salt Lake City, UT, USA

\section{References}

1. Brown D, Ellerton J, Paal P, Boyd J. Hypothermia evidence, afterdrop, and practical experience. Wilderness Environ Med. 2015;26:439-440.

2. Zafren K, Giesbrecht GG, Danzl DF, et al. Wilderness Medical Society practice guidelines for the out-of-hospital evaluation and treatment of accidental hypothermia: 2014 update. Wilderness Environ Med. 2014;25(Suppl):66-85. 
3. Hayward JS, Eckerson JD, Kemna D. Thermal and cardiovascular changes during three methods of resuscitation from mild hypothermia. Resuscitation. 1984;11:21-33.

4. Giesbrecht GG, Bristow GK. The convective afterdrop component during hypothermic exercise decreases with delayed exercise onset. Aviat Space Environ Med. 1998;69:17-22.

5. Guyatt G, Gutterman D, Baumann MH, et al. Grading strength of recommendations and quality of evidence in clinical guidelines: report from an American College of Chest Physicians Task Force. Chest. 2006;129:174-181.

6. Althaus U, Aeberhard P, Schupbach P, Nachbur BH, Muhlemann W. Management of profound accidental hypothermia with cardiorespiratory arrest. Ann Surg. 1982;195:492-495.

7. Stoneham MD, Squires SJ. Prolonged resuscitation in acute deep hypothermia. Anaesthesia. 1992;47:784-788.

8. Giesbrecht GG, Hayward JS. Problems and complications with cold-water rescue. Wilderness Environ Med. 2006;17:26-30.

9. Giesbrecht GG, Bristow GK. A second postcooling afterdrop: more evidence for a convective mechanism. J Appl Physiol. 1992;73:1253-1258.

\section{The Hand-Powered Ring Cutter: A Useful Tool in Your Wilderness Medical Bag}

\section{To the Editor:}

A gentleman in his mid-40s presented with a left fourth finger injury to the medical team at the finish line of a 50-mile mountain bike race. He reported dislocation of his left fourth proximal interphalangeal joint (PIPJ) as a result of a fall during the race. He was able to self-reduce his finger immediately. Despite severe pain and swelling, he completed the race. On arrival to the medical station, there was no joint deformity, but he had significant edema of his fourth finger on examination, with a ring that was not removable. He was very tender over the PIPJ, and the neurovascular condition of the finger was intact. The ring was removed using a hand-powered ring cutter (Figure).

Finger injuries are among the most common musculoskeletal injuries in endurance athletes. If the injury happens while the athlete is wearing a ring, immediate removal of the ring is important to prevent constriction syndrome. ${ }^{1}$ Most cases of digital constriction (tourniquet) syndromes occur in infants and mentally ill patients. ${ }^{2,3}$ Delay in presenting for medical attention may happen for a variety of reasons. ${ }^{2-4}$ Etiologies of digital tourniquet syndrome include external constricting bands (eg, metal, plastic, hair) and traumatic, infectious, endocrinologic, allergic, rheumatologic, and dermatologic conditions. ${ }^{1,2}$ Treatment of an acute edematous finger with a constricting ring requires urgent intervention. Neurovascular examination of the affected digit is important. The ring can be removed with less-invasive methods like distal

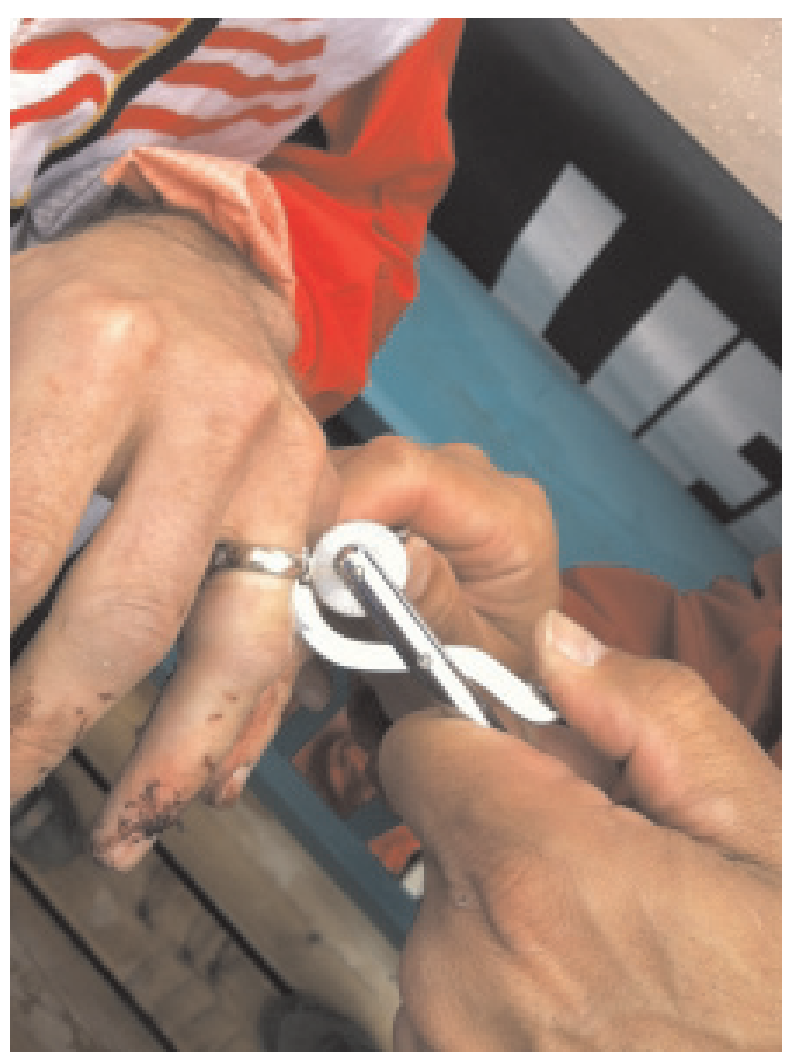

Figure. Removal of the trapped ring by a hand-powered ring cutter.

lubrication (eg, soap, mineral oil, and lubricant gel), distal edema reduction (eg, elevation of the affected extremity, ice, compression of the distal area to the ring), sequential compression (eg, dental floss, sutures, elastic tapes, and string-wrap methods), and surgical glove method. ${ }^{1,5}$ If these methods are unavailable or unsuccessful, division of the constricting band is necessary. ${ }^{1,5}$ This can be achieved by a cutting tool or a saw (hand-powered or motorized). A hand-powered ring cutter is an easy-to-use tool that can be added to a medical bag as in our case.

\section{Acknowledgment}

The authors would like to thank Mr. George Gipson.

Morteza Khodaee, MD, MPH Jill Tirabassi, MD

University of Colorado School of Medicine Denver, CO, USA

\section{References}

1. Peckler B, Hsu CK. Tourniquet syndrome: a review of constricting band removal. J Emerg Med. 2001;20:253-262. 